Document downloaded from:

http://hdl.handle.net/10251/79452

This paper must be cited as:

Galindo-Galiana, B.; Benedito, A.; Giménez Torres, E.; Compañ Moreno, V. (2016). Comparative study between the microwave heating efficiency of carbon nanotubes versus multilayer graphene in polypropylene nanocomposites. Composites Part B: Engineering. 98:330-338. doi:10.1016/j.compositesb.2016.04.082.

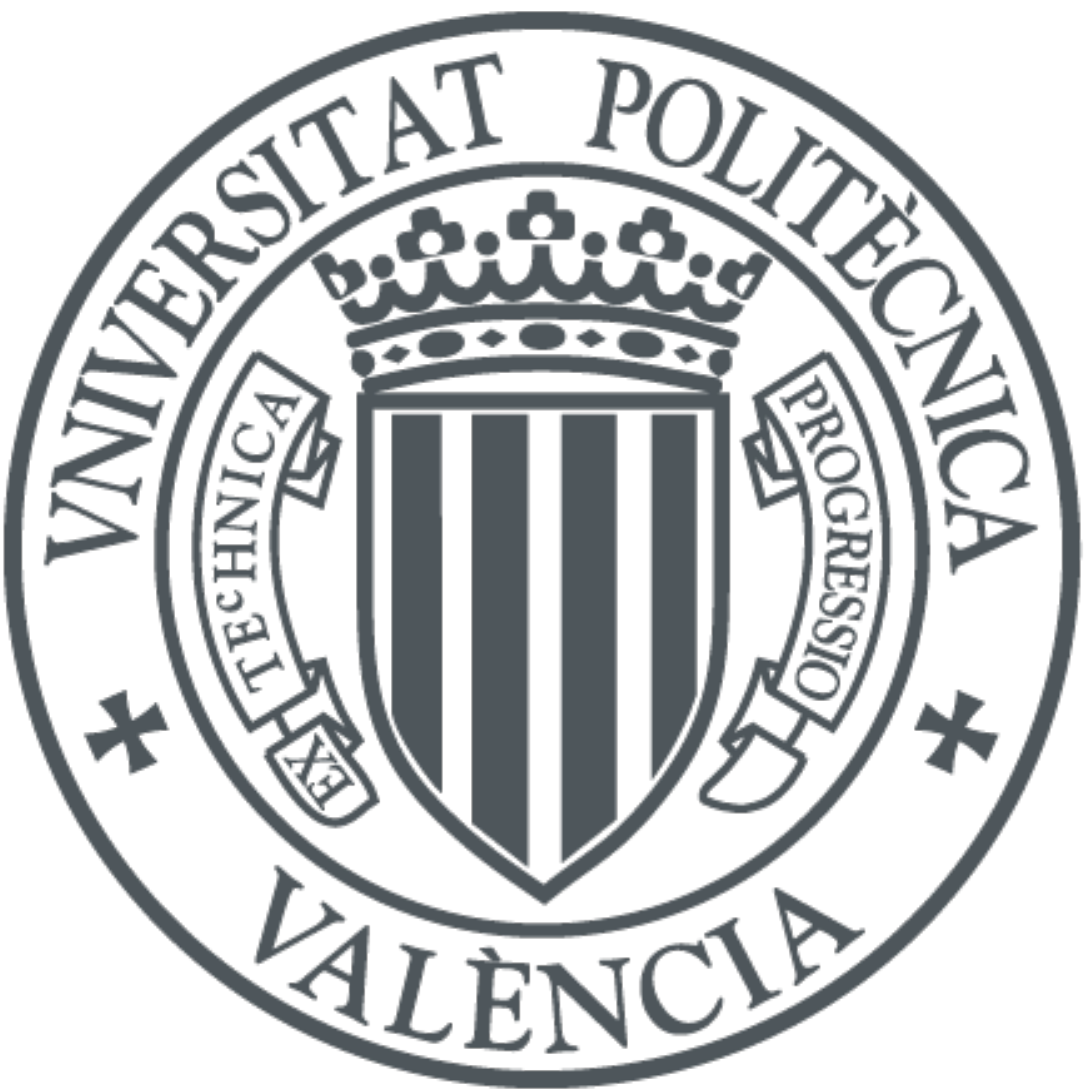

The final publication is available at

http://dx.doi.org/10.1016/j.compositesb.2016.04.082

Copyright Elsevier

Additional Information 
Part B

Elsevier Editorial System(tm) for Composites

Manuscript Draft

Manuscript Number:

Title: COMPARATIVE STUDY BETWEEN THE MICROWAVE HEATING EFFICIENCY OF CARBON NANOTUBES VERSUS MULTILAYER GRAPHENE IN POLYPROPYLENE NANOCOMPOSITES

Article Type: Full Length Article

Keywords: Particle-reinforcement

Electrical properties

Physical properties

Thermal properties

Extrusion

Corresponding Author: Miss. Begoña Galindo Galiana,

Corresponding Author's Institution: AIMPLAS

First Author: Begoña Galindo Galiana

Order of Authors: Begoña Galindo Galiana; Adolfo Benedito Borrás;

Vicente Compañ Moreno; Enrique Gimenez Torres

Abstract: Multiwall carbon nanotubes (MWCNT) and multilayer graphene (MLG) were studied as microwave susceptor additives for polymers.

Different percentages of both nanoparticles were added to polypropylene by melt compounding in order to study the microwave absorption and the polymer heating. Polypropylene was selected as polymer matrix due to its unpolar nature to avoid the influence of polymer polarity and evaluate the influence of the nanoparticles. Electrochemical spectroscopy impedance measurements were carried out to evaluate the conductive and dielectric properties of nanocomposites. Results showed that nanocomposites with higher electrical conductivity have better capacity of absorbing microwave radiation. High values of permittivity and loss tangent also increases the microwave radiation absorption and the ability of the material to convert this electromagnetic radiation into heat. Carbon nanotubes showed better microwave susceptor behavior than graphene multilayer. Nanocomposites with 1\% w/w of carbon nanotubes can be compared with the heating efficiency of a polypropylene filled with $10 \%$ $\mathrm{w} / \mathrm{w}$ of multilayer graphene. The higher efficiency of carbon nanotubes it is explained by their higher electrical conductivity and optimal dielectric properties of the nanocomposites compared to multilayer graphene polymer systems.

Suggested Reviewers: Christian Beauger christian.beaugeramines-paristech. fr

Leoncio Garrido

lgarridodcetef.csic.es

Santiago Lafuente

luiss@uji.es 
Opposed Reviewers: 
Composites Part B: Engineering

Paterna, $10^{\text {th }}$ December, 2015

Dear Sir/Madam,

I am pleased to submit the manuscript "COMPARATIVE STUDY BETWEEN THE MICROWAVE HEATING EFFICIENCY OF CARBON NANOTUBES VERSUS MULTILAYER GRAPHENE IN POLYPROPYLENE NANOCOMPOSITES". This article is a compilation of the results obtained from the collaboration of AIMPLAS with the Polytechnic University of Valencia. In the present study we were aiming to analyze the use of multilayer graphene and multiwall carbon nanotubes as microwave susceptor additive for polymers. Electrical conductivity and dielectric properties have been correlated with the ability of the nanofiller to absorb microwave radiation. Reviewers in nanocomposites field and dielectric properties characterization may be interested in the article.

Thank you in advance for your time and interest in our research.

Sincerelly,

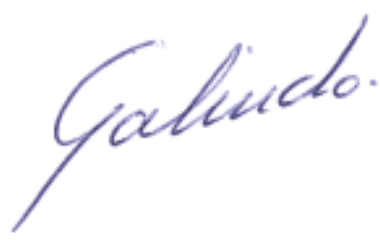

Begoña Galindo Galiana

AIMPLAS (Technological Institute of Plastics)

46980 Paterna

Valencia (Spain) 
1

\title{
“COMPARATIVE STUDY BETWEEN THE MICROWAVE HEATING EFFICIENCY OF CARBON NANOTUBES VERSUS MULTILAYER GRAPHENE IN POLYPROPYLENE NANOCOMPOSITES"
}

\author{
Begoña Galindo ${ }^{1}$, Adolfo Benedito ${ }^{1}$, Enrique Gimenez ${ }^{2}$, Vicente Compañ ${ }^{3}$ \\ ${ }^{1}$ AIMPLAS Technological Institute of Polymers, Valencia, Spain \\ ${ }^{2}$ Department of Mechanical and Material Engineering, Universidad Politécnica de Valencia, 46022 Valencia, Spain \\ ${ }^{3}$ Department of Applied Thermodynamics, Universidad Politécnica de Valencia, 46022 Valencia, Spain
}

\begin{abstract}
Multiwall carbon nanotubes (MWCNT) and multilayer graphene (MLG) were studied as microwave susceptor additives for polymers. Different percentages of both nanoparticles were added to polypropylene by melt compounding in order to study the microwave absorption and the polymer heating. Polypropylene was selected as polymer matrix due to its unpolar nature to avoid the influence of polymer polarity and evaluate the influence of the nanoparticles. Electrochemical spectroscopy impedance measurements were carried out to evaluate the conductive and dielectric properties of nanocomposites. Results showed that nanocomposites with higher electrical conductivity have better capacity of absorbing microwave radiation. High values of permittivity and loss tangent also increases the microwave radiation absorption and the ability of the material to convert this electromagnetic radiation into heat. Carbon nanotubes showed better microwave susceptor behavior than graphene multilayer. Nanocomposites with $1 \% \mathrm{w} / \mathrm{w}$ of carbon nanotubes can be compared with the heating efficiency of a polypropylene filled with $10 \% \mathrm{w} / \mathrm{w}$ of multilayer graphene. The higher efficiency of carbon nanotubes it is explained by their higher electrical conductivity and optimal dielectric properties of the nanocomposites compared to multilayer graphene polymer systems.
\end{abstract}

\author{
ABBREVIATIONS \\ MWCNT: Multiwall Carbon Nanotubes \\ MLG: Multilayer Graphene \\ CVD: carbon vapor deposition \\ PP: polypropylene \\ SEM: scanning electron microscopy
}

TEM: transmission electron microscopy

ISE: impedance spectroscopy electrochemical

\section{INTRODUCTION}

Microwave technology is an alternative to conventional heating methods with important advantages like penetrating radiation, controllable electric field distribution, rapid heating, selective heating of materials and self-limiting reactions ${ }^{1}$. Nevertheless, microwaves also present important disadvantages, mainly related to the lack of uniform and selective heating over a large volume and the transparency of most of the materials to microwaves. In order to improve the heating homogeneity it is necessary to understand the heating mechanism. The energy involved in the process is supplied by an electromagnetic field that interacts with the material. Two major effects are responsible of the material heating ${ }^{2}$ :

- Dipolar polarization: the charged particles cannot move in the space. In that case, this limited displacement provokes the orientation of particle in the opposite region balancing the electric force. The result is a dipolar polarization in the material. Magnetic polarization can also contribute to heating effect in the case of materials with magnetic properties. 
- Conduction: it happens when the charged particles are free to travel through the material. For example, electrons in carbonous substances. This movement induces a current that travel in phase with the electromagnetic field.

Therefore, material properties are of greatest importance in microwave processing, being the electrical conductivity and the dielectric properties very influencing properties on the heating behavior under microwave radiation. The complex relative permittivity $\varepsilon=\varepsilon$ ' $-j \varepsilon$ " and the loss tangent, tan $\delta=\varepsilon^{\prime \prime} / \varepsilon^{\prime}$ are critical to study the interaction between the electric field and the dipoles of the material. The real part of the permittivity, $\varepsilon^{\prime}$, called the dielectric constant, mostly determines how much of the incident energy is used in the dipole rotation. The most important for a material is to look for a frequency where the absorption of energy will be high, $\varepsilon^{\prime}$, and the energy loss, $\varepsilon$ '. This equilibrated frequency point is well defined by the loss tangent, tan $\delta$, or dielectric loss, which predicts the ability of the material to convert the incoming energy into heat ${ }^{3}$.

Most thermoplastics are transparent to microwaves. Polymers do not absorb microwaves to a sufficient extent to be heated as exhibit very low dielectric losses in the $\mathrm{GHz}$ region. Using specific fillers can increase the susceptibility of common polymers to microwave processing ${ }^{4}$. These additives are conductive, or have dielectric properties significantly different from the matrix polymer. The presence of these inclusions strongly influence on the interaction of composite material with the microwave radiation. Some examples of these conductive additives include carbon black ${ }^{5,6}$, metal fibres $^{7}$, silicium carbide ${ }^{8}$, titanium dioxide and others ${ }^{9}$. The effect of conductive additives on microwave heating depends on the size, shape, concentration, electrical conductivity and dielectric properties of the inclusions and their distribution in the matrix. Carbonise particles are excellent microwave susceptors showing high permittivity values $\left(\varepsilon^{\prime}\right)$ and high values of loss tangent $(\tan \delta)^{10,11,12}$.

Several studies have been found regarding the use of carbon nanotubes as polymer microwave susceptor additive. P. Zhinhua et al ${ }^{13}$ incorporated MWCNT in polystyrene matrix. These authors found that $2.487 \% \mathrm{w} / \mathrm{w}$ of canbon nanotubes considerably increases the dielectric properties of polyestirene in a frequency range of $50 \mathrm{MHz}-3 \mathrm{GHz}$. Z. Fan et al ${ }^{14}$ analyzed the influence of carbon nanotubes on the microwave radiation capacity of polypropylene, polyethylene and polyethylenetereftalate. Loss tangent of nanocomposites in creased with the content of carbon nanotubes in all the polymer systems. The optimal content of carbon nanotues was found to be $4 \%$ $\mathrm{w} / \mathrm{w}$. Polyethylene tereftalate showed higher microwave radiation absorbance than polyolefines due to its polarity.No study was found regarding the use of multilayer graphene as microwave susceptor additive for thermoplastic polymers.

The aim of the present work consist of studying the properties of carbon nanotubes and multilayer graphene nanoparticles as microwave susceptors. Dielectric properties of the nanocomposites are being studied to predict microwave absorption and heating effectiveness for this the heating effectiveness of both nanoparticles are being studied just to know the differences when they are compared. Polypropylene ${ }^{15}$ was selected as matrix due its non-polar nature and microwave transparency and the nanocomposites were prepared by melt mixing procedure using a co-rotative twin-screw extruder. Multiwall carbon nanotubes (MWCNT) and multilayer graphene (MLG) were studied as microwave susceptor due to their high electrical properties.

\section{EXPERIMENTAL}

\subsection{Materials}

NC7000 multiwall carbon nanotubes (MWCNT) were purchased from the Belgium Company Nanocyl. These MWCNT are produced via catalytic carbon vapour deposition (CVD) process with an average diameter of $9.5 \mathrm{~nm}$, length of $1.5 \mu \mathrm{m}$ and carbon purity around $90 \%$. Multilayer graphene (MLG) was purchased from XGScience. Grade $M$ with a diameter of $5 \mu \mathrm{m}$ was selected for the trials, which is claimed to have high thermal and electrical properties. Homopolymer polypropylene was selected as polymer matrix. The employed grade was PP DUCOR 1101S from DUCOR Petrochemicals. This material has a MFR $(230 \mathrm{oC} / 2.16 \mathrm{~kg})$ of $25 \mathrm{~g} / 10 \mathrm{~min}$, a tensile modulus of 1500 $\mathrm{MPa}$ and a melting point of $163^{\circ} \mathrm{C}$. 


\subsection{Sample preparation}

Nanocomposites with different percentages of MWCNT and MLG were obtained in a co-rotative twin screw extruder COPERION W\&P ZSK25. The extruder has a diameter of $25 \mathrm{~mm}$ and an L/D ratio of 40 . MWCNT nanocomposites were produced with a nanoparticle loading of $0.5 \%, 1 \%, 3 \%$ and $5 \%$. MLG nanocomposites were obtained with $0.5 \%, 1 \%, 3 \%, 5 \%$ and $10 \%$ of filler loading. Nanocomposites were produced with the same processing conditions. The nanoparticles were incorporated via masterbatch which was produced in a previous process. Two masterbatches with a MWCNT loading of $15 \%$ and a MLG loading of $15 \%$ were produced under the following conditions: highly dispersive screw configuration, $600 \mathrm{rpm}$ and temperature profile $260{ }^{\circ} \mathrm{C} / 220{ }^{\circ} \mathrm{C} / 220{ }^{\circ} \mathrm{C}$ $1210^{\circ} \mathrm{C} / 200{ }^{\circ} \mathrm{C} / 190^{\circ} \mathrm{C}$. Masterbatch dilutions were processed with the same temperature profile and the screw as the masterbatc. The screw speed was increased up to $800 \mathrm{rpm}$ to ensure the nanoparticles dispersion. Test bars were produced by compression moulding in a hot press (COLLIN model P200E) at $200{ }^{\circ} \mathrm{C} / 15$ bars during 15 min. Samples with dimensions of $(10 \times 1 \times 0.4)$ $\mathrm{cm}$ were used in morphology characterization and electrical conductivity studies.

\subsection{Characterization techniques}

The dispersion of MWCNT and MLG in the nanocomposites was examined by optical microscope $(\mathrm{OM})$, scanning electron microscopy (SEM) and transmission electron microscopy (TEM). Dispersion analysis was carried out on the samples with $1 \%$ of nanoparticles as the matrix is not collapsed with nanoparticles and it is possible to analyse individual particle size and homogeneity.

Optical microscope analysis was done on samples with disc shape of $2.5 \mathrm{~cm}$ of diameter and 100 $\mu \mathrm{m}$ of thickness were prepared in a hot plate press at $210{ }^{\circ} \mathrm{C}$ for 3 minutes. The microscope employed was LEICA model DMRX equipped with software of image analysis (Leica Materials Workstation $\vee$ 3.6.3). The parameters measured in the samples were mean particle size and agglomerates density. Agglomerate density makes reference to the area of the sample, which is occupied by aggregates in relation to the total area of the sample. It is calculated with the following formula ${ }^{16}$ :

$$
\text { Agglomerates density }=\frac{A_{x}}{A_{0}} \times 100 \quad \text { Eq. } 1
$$

Where $A_{x}$ is the area of the sample with CNT agglomerates and $A_{0}$ is the total area of the sample.

Scanning Electron Microscopy (SEM) studies were performed with a Phenom Pro X desktop microscope. The microscope works at multiple acceleration voltage $(5,10,15 \mathrm{kV})$, reaching a resolution of less than $12 \mathrm{~nm}$. The samples were prepared by cryogenic fracture of compression moulding test bars and subsequent coated with gold by sputter coating technology.

The dielectric properties of the nanocomposites with different percentages of MWCNT and MLG were measured by impedance spectroscopy at $20^{\circ} \mathrm{C}, 30^{\circ} \mathrm{C}, 40^{\circ} \mathrm{C}, 50^{\circ} \mathrm{C}$ and $60^{\circ} \mathrm{C}$ of temperature, in the frequency range $10^{-1}<\mathrm{f}<3 \times 10^{6} \mathrm{~Hz}$ with $0.1 \mathrm{~V}$ amplitude, using a Novocontrol broadband dielectric Spectrometer (Hundsangen, Germany) integrated by a SR 830 lock-in amplifier with an Alpha dielectric interface. The temperature was controlled by nitrogen jet (QUATRO from Novocontrol) with a temperature error of $\approx 0.1 \mathrm{~K}$ during every single sweep in frequency. The measurements have been made using a dry procedure where the sample of interest was sandwiched between two gold circular electrodes coupled to the impedance spectrometer acting as blocking electrodes. The assembly membrane-electrode was annealed in the Novocontrol setup under an inert dry nitrogen atmosphere previously to the start of the actual measurement. For this the temperature was two times firstly and gradually raised and lowered from $20^{\circ} \mathrm{C}$ to $60^{\circ} \mathrm{C}$ in steps of $10^{\circ} \mathrm{C}$. At the third cycle of temperature scan, the dielectric spectra were collected in each step. This was performed to ensure the measurements reproducibility. 


\subsection{Microwave heating}

Microwave heating trials were carried out in a $5.8 \mathrm{GHz}$ multimode microwave provided from the German company FRICKE\&MALLAH. $5.8 \mathrm{GHz}$ microwave system was selected instead of 2.45 $\mathrm{GHz}$ due to the sample geometry. Microwave radiation at $5.8 \mathrm{GHz}$ has less penetration and higher intensity than $2.45 \mathrm{GHz}$ which makes the system more adequate to heat thin geometries as polymer pellets. The maximum power of the microwave was $700 \mathrm{~W}$ and the oven cavity had the following dimensions: $(300 \times 320 \times 195) \mathrm{mm}$. Samples in pellet form were exposed to microwaves for a period of $20 \mathrm{~s}, 40 \mathrm{~s}$ and $60 \mathrm{~s}$ at a maximum power. This process was repeated six times for each sample and five temperature data were obtained each time. Mean temperature was calculated with all the values obtained. $50 \mathrm{~g}$ of nanocomposite pellets were placed in the centre of the cavity to ensure heating homogeneity, which was assessed with a thermochromic disc paper. Temperature increase in the microwave chamber was monitored with an infrared camera FILR ThermaCAM P640 $(\varepsilon=0.95)$.

\section{RESULTS AND DISCUSSIONS}

\subsection{Morphology analysis of Nanocomposites}

Morphology of nanocomposites with 1\%w/w of MLG and MWCNT was analysed with optical and electronic scanning microscope. Figure 1 shows the SEM pictures for polypropylene with $1 \% \mathrm{w} / \mathrm{w}$ of MLG. In Figure 1a the MLG flakes are aligned in the same direction and there is no evidence of nanoparticle agglomeration. Figure $1 \mathrm{~b}$ shows a MLG flake in detail and it can be appreciated the flakes stacked forming the MLG particle. Morphological analysis of PP with $1 \% \mathrm{w} / \mathrm{w}$ of MWCNT are shown in Figure $2 \mathrm{a}$ and $2 \mathrm{~b}$. MWCNT are dispersed within the polymer matrix as individual nanoparticles but some agglomerates or bundles are shown in the SEM pictures. Figure $2 b$ highlights theses agglomerates.

Optical microscope analysis was carried out in order to analyse the dispersion with a quantitative method. Figures $3 a$ and $3 b$ correspond to PP with $1 \% \mathrm{w} / \mathrm{w}$ of MLG and $1 \% \mathrm{w} / \mathrm{w}$ of MWCNT, respectively. These pictures were analysed with a software of particle analysis to obtain the mean particle size and the agglomerates density. These data is compiled in Table 1.

Analysing the data of Table 1 and Figure $3 a$ and $3 b$ it can be concluded that MWCNT nanocomposite has bigger agglomerates but the number of agglomerates is much lower. This results in a lower area of the matrix covered by agglomerates which can be seen in the optical microscope. MLG particles are nano in z direction but $x-y$ plane is large which increases the aspect ratio of the particles and increases their effectiveness at low percentage. For this reason it can be seen more number of particles of MLG in optical microscope (Figure 3a) than the number of particles shown for MWCNT nanocomposite (Figure 3b).

\subsection{Dielectric properties of nanocomposites}

Impedance spectroscopy electrochemical (ISE) measurements were carried out for the samples of MWCNT nanocomposites with a nanoparticle loading of $0.5 \%, 1 \%, 3 \%$ and $5 \%$ and for the samples of MLG nanocomposites obtained with $0.5 \%, 1 \%, 3 \%, 5 \%$ and $10 \%$ of filler loading at different temperatures in order to obtain information on their conductive properties. The data was analyzed in terms of their dielectric permittivity $\varepsilon^{*}=\varepsilon^{\prime}-\mathrm{j} \varepsilon^{\prime \prime}$, as well as the complex conductivity $\sigma^{*}=\sigma^{\prime}+j \sigma^{\prime \prime}$, where $\varepsilon^{\prime}$ and $\varepsilon$ " represent the real and imaginary parts of the permittivity, $\sigma^{\prime}$ and $\sigma^{\prime \prime}$ are the real and imaginary parts of the conductivity and $\mathrm{j}$ the imaginary unity. From the imaginary part of the permittivity we can obtain the conductivity-dc $\left(\sigma_{d c}\right)$, as for a pure Ohmic conduction $\varepsilon "=\sigma_{d d} /\left(\varepsilon_{0} \omega\right)$, where $\varepsilon_{0}$ represents the permittivity of vacuum and $\omega$ the angular frequency of the applied electric field. In general, the modelling of the dielectric loss spectra in polymer electrolyte membranes can be separated in three different regions: high, medium and low frequencies, respectively ${ }^{15}$. The dependence of the real part of the conductivity $\left(\sigma^{\prime}\right)$, is characterized on the high frequency side by a plateau, the value of which directly yields the dc conductivity, $\sigma_{\mathrm{dc}}$ where the phase angle turn to an value of zero, and the characteristic radial frequency, $\omega_{c}=2 \pi f_{c}$, at which dispersion sets in and turns into a power law at higher frequencies. On the other hand, the real part of the dielectric function $\varepsilon$ ' at 
$\mathrm{f}_{\mathrm{c}}$ turns from the high frequency limit to the static value $\varepsilon_{\mathrm{s}}$, which represent the permittivity of the material. At lower frequencies, it is observed that $\sigma^{\prime}$ decreases from $\sigma_{\mathrm{dc}}$ and this is due to electrode polarization that results from blocking of charge carriers at the electrodes ${ }^{16}$. When the behaviour of the sample is capacitive the variation of the impedance with the frequency is completely a straight line with slope -1 . However when the sample has a conductive behaviour the impedance, in all the range of the frequencies, will be constant even varying the temperature.

In many cases the Maxwell-Wagner-Sillers (MWS) ${ }^{17-20}$ contribution dominates due to the bulk conductivity of the free charge carriers. When the MWS effects dominates completely over the effects of surface polarization and internal relaxations in the polymer, then we have

$$
\varepsilon^{*}=\varepsilon_{s}+\frac{\sigma_{d c}}{j \varepsilon_{0} \omega}
$$

This can be seen by the fact that the plot of the double logarithm of the dielectric loss ( $\varepsilon ")$ versus frequency exhibits a slope of ca.-1, such is the behaviour of the nanocomposite PP+ MWCNT for all concentrations of filler MWCNT and all temperatures studied. In this sense, in Figure 4 the double logarithmic plots of the imaginary permittivity $\varepsilon$ " versus the frequency are given for all the samples with MWCNT at $50^{\circ} \mathrm{C}$. From this figure we can see that the behavior of PP+MWCNT samples, for all the amounts of MWCNT is linear in the complete range of frequencies with an slope independent of the amount of nanoparticle loading. The slope of the straight line is practically -1 for all the temperatures studied with a correlation coefficient ca. 0.999. This is the typical contribution to the dielectric loss from electrical conduction, which is mean that the behaviour of the PP+MWCNT samples is as pure conductor ${ }^{20}$. To probe this affirmation we can see in the same plot the phase angle and observe that its value is constant and equal to 0 in practically all the range of frequencies. From the intercepts of the lines showed in figure 5 (at a low frequency p.e. $1 \mathrm{~Hz}$ ), we can obtain the values of the conductivity for the nanocomposites. The values obtained are given in table.2. These values change very little with the temperature, and increase 1000 times when the amount of filler in percentage increase only 10 times. For example the conductivity take the value of $2 \times 10^{-6} \mathrm{~S} / \mathrm{cm}$ for PP+ $0.5 \%$ MWCNT and $2 \times 10^{-3} \mathrm{~S} / \mathrm{cm}$ in case of PP+5\% MWCNT.

The opposite effect is seen in the samples of MLG where the $\log \varepsilon$ " vs. $\log f$ plot give a dispersion around the value of zero for the imaginary part of the permittivity, that is mean which samples of nanocomposites PP+MLG have a behaviour of a capacitor, such behavior is shown in figure $6 a$, where the plot of the absolute value of impedance $|Z|=\left[\left(Z^{\prime}\right)^{2}+\left(Z^{\prime \prime}\right)^{2}\right]^{1 / 2}$, as a function of the logarithm of frequency (Bode plot) where we can see that the phase angle plot reach the value constant of 90 . The dielectric response of the impedance with the logarithm of frequency varies linearly in all the range of frequency for samples where the amount of fillers is less than $10 \%$ of Grafhene. The Bode diagram shown in figures $6 a$ is a typical behavior of a parallel $R_{0} C$ circuit at which $\omega R_{0} C>>1$ where

$$
\log |Z *|=\log \left|\frac{R_{0}}{1+j R_{0} C \omega}\right|=\log \frac{1}{C \omega}=\log \left(\frac{1}{2 \pi C}\right)-\log f
$$

From the results showed in figure 6 we can conclude that this response is purely capacitative and the impedance is directly proportional to the frequency with a slope around -1 with a correlation coefficient ca. 0.999 in practically all concentrations and at everyone temperature studied. This is a field of study of great interest in the case of materials to use as electrolytes for capacitors and supercapacitors $^{21}$. However, when the amount of MLG is $10 \%$ the impedance in the Bode diagram tends to a constant value in the region of low frequencies, that is mean that the sample behaviour is conductive but with a very low conductivity such as we can observe from the higher impedance value obtained by the intersection between the impedance modulus when the frequency tend to zero (around $10^{8} \Omega$ ) where the conductivity reach the low value of $3 \times 10^{-9} \mathrm{~S} / \mathrm{cm}$. . At the same time, the phase angle increases from $-90^{\circ}$ to $0^{\circ}$ at the low frequencies region. The critical frequency, (ca. $\omega=180 \mathrm{rad} / \mathrm{s}$ ) was taken as the value at which the impedance modulus is constant. 
When we change the MLG filler by MWCNT the behavior of the impedance is very different to observed in Figure 5, such as we can see from figure 6, where the samples PP+MWCNT are now analyzed. From this figure 6 we can see that the samples PP+MWCNT behavior is as a conductor material with different resistance in function of the amount of fillers that we have in the nanocomposite. The resistance of each one of nanocomposites can be obtained from the intercept in the Z-axis, i.e. from the intersection of the extrapolated frequency-independent plateau line and the $\log |z|$ axis. Notice that in case of to have an amount of fillers lowest $1 \%$ or minor, then in the high frequencies region the tendency is to change from the resistor to a capacitor behavior. The critical frequency is function of the amount of MWCNT fillers. In our study we can observe that when the amount of CNT filler is $0.5 \%$ the critical frequency is ca. to $40000 \mathrm{~Hz}$ while in case of $1 \%$ this value increase to $100000 \mathrm{~Hz}$.

From the straight lines of figure 5 with slope c.a. -1 we are calculated from the intercept, according eq.(2), the values of the geometrical capacitance, $C$ for all the samples PP+MLG. The values obtained are represented in function of the filler concentration in Figure 7, where we can see a linear behaviour with the amount of MLG incorporated into the matrix of polypropylene.

The Figure 8 shows the study of frequency dependence of the real part of the permittivity $\left(\varepsilon^{\prime}\right)$ with the frequency shows that the permittivity is practically constant with the temperature, in all the range of temperatures studied, when in the nanocomposite the filler is MLG. However, a close inspection of this variations shown that the real part of the permitivitty $\left(\varepsilon_{s}\right)$, changes from 3.4 for the sample PP+MLG0.5\% to 10.7 in case of PP+MLG10\%.

However the changes with the amount and kind of fillers are more important in case of nanocomposites PP+MWCNT, where such is observed from figure 9 the permittivity change from values practically constant with the temperature for samples with MLG to important differences when the filler is substituted by MWCNT. For example the permittivity was 22 for samples $\mathrm{PP}+\mathrm{MWCNT}$ of $0.5 \%$ at $20^{\circ} \mathrm{C}$, changing very little with the temperature where at $60^{\circ} \mathrm{C}$ this value was around 27 . However, the permittivity increase until 104 when the amount of MWCNT is the $5 \%$ at $20^{\circ} \mathrm{C}$ and this value is about of 169 at $60^{\circ} \mathrm{C}$ of temperature. Therefore, when the polymer PP was modified adding different percentages of CNT appears an increasing of the polarity compared with the base-polymer and even with PP+MLG. Only the case of $0,5 \%$ of MWCNT fillers give values of the permittivity comparable with MLG for the other concentration of CNT the results are significant.

Finally, the effect of the polarity of fillers in PP on the microwave heating of materials containing them is related to their dielectric constants. Accordingly, the heating effect of microwave can be considered as a property that is directly related to their dielectric loss factor $\varepsilon$ ", or in this regard is better consider the values of loss tangent $\left(\tan \delta=\varepsilon^{\prime \prime} / \varepsilon^{\prime}\right)$ where the two parameters are include. For this, the last parameter, $\tan \delta$, determines the capacity of a given material to be heated under microwave irradiation ${ }^{22}$. Figure 9 shows the variation of the loss tangent with the amount of filler concentration for all temperatures studied. In all the cases, an increase in this parameter with the percentage of MWCNT as filler has been observed for all the temperatures. However when the filler is MLG the values of tan $d$ is very little or practically zero for all the concentrations and temperatures. Similar behavior has been recently reported for bulk $1 \mathrm{~s}^{23,24}$. A close inspection of the figure 10 shows the same behavior observed on the variation of the real part of the permittivity, where an increasing in the loading of the filler is accompanied by an increase in the tan $\delta$ value and, simultaneously, by a higher heating efficiency. Thus, the experimental effect observed upon microwave heating can be correlated with the values of $\varepsilon^{\prime}, \varepsilon^{\prime \prime}$ and Tan $\delta$. Values that we are obtained from the impedance dielectric measurements.

\subsection{Heating efficiency}

Nanocomposites were exposed to microwave for different heating times in order to evaluate the temperature increase of the sample. Each experiment was repeated 10 times. The final temperature value was the mean the temperature measured on five points of the sample. Figure 10 represents the temperatures achieved with nanocomposites filled with different MWCNT percentage at different heating times. The temperature of MWCNT nanocomposites gradually increases as the percentage of MWCNT is increased. This behaviour is not shown in MLG nanocomposites. The temperature 
does not increase with nanocomposites with $0.5 \%, 1 \%$ and $3 \%$ of MLG even at longer microwave exposure times. Temperatures start increasing at $5 \%$ of MLG but the most representative rise is achieved at $10 \%$ of MLG which is also in accordance with the electrical conductivity values. The behaviour of MLG nanocomposites is shown in Figure 11. For MLG the percolation threshold as microwave susceptor is $5 \% \mathrm{w} / \mathrm{w}$ while MWCNT shows microwave susceptor properties at $0.5 \%$ w/w.

Heating efficiency is calculated as the slope of the represented curves in ${ }^{\circ} \mathrm{C} / \%{ }^{17}$. The values of heating efficiency at different heating times are compiled in table 3 . The effectiveness of MWCNT is much higher compared to MLG. The microwave susceptor properties are correlated to the electrical and dielectric properties. Higher mobility of electrons and dipole rotation shown in MWCNT nanocomposites are reflected in the microwave heating trials by absorbing more electromagnetic radiation and obtaining a higher increase of the temperature of the nanocomposite.

Microwave heating of polymers is aiming to decrease the energy consumption during polymer processing. Therefore, the microwave susceptor has to be able to achieve polymer melt temperature in a short period of time taking into account that this time must be similar or lower to the residence time of the polymer in a injection moulding machine or into an extruder. It is important to point out that MLG nanocomposites do not reach the melt temperature of polypropylene even with $10 \% \mathrm{w} / \mathrm{w}$ at the longest exposure times. Thus, this nanocomposites are not suitable for microwave processing.

\subsection{Heating homogeneity}

Heating homogeneity is also a very important factor to take into account for selecting the most suitable percentage of a microwave susceptor. Heating efficiency without evaluating the homogeneity of the temperature in the sample is an incomplete study as hot spots may increase the mean temperature of the material. If the microwave susceptor is not well dispersed the consecuence may be the formation of hot spots during the microwave expossure. Hot spots are a problem during production as some parts of the material may be burnt and the physical properties of the product may not be homogeneous. As mentioned previosly, ten temperatures were registered from each experiment (10 experiments for each nanocomposite). Figures 12 and 13 represent the stadistic data of the experimentos of MWCNT and MLG respectively. Microwave heating of MLG nanocomposites is less effective than MWCNT but the temperature values of the samples are very similar during the microwave expossure. It can be said that there are no hot spots in the sample. The drawback of MLG as microwave susceptor is that the nanocomposite do not reach the melt temperature to polypropylene.

In case of MWCNT nanocomposites, Figure 13 shows a different behavior at low MWCNT content compared with high content of nanoparticles. 1\% of MWCNT may be considered the optimum content for microwave susceptor. Heating homogeneity of the samples is very homogeneous and the temperature incresement is less dramatic so the heating process can be easily controlled. The lack of hot spots make this $1 \% \mathrm{w} / \mathrm{w}$ of MWCNT the most suitable susceptor additive content. At higher MWCNT content some hot spots appear during microwave heating of MWCNT nanocomposites. Nanoparticles agglomerates may be responsible for these hot spots. Fast heating is observed at high percentage of MWCNT but the sample shows burnt parts which makes the final properties not controllable.

\section{CONCLUSIONS}

Multiwall carbon nanotubes provides better performance as microwave radiation susceptor additive for polypropylene matrix compared with multilayer graphene. The temperature reach by the nanocomposite after 1 minute of radiation is higher for the MWCNT systems. It can be said that $0.5 \% \mathrm{w} / \mathrm{w}$ of MWCNT show similar behavior in the microwave than a nanocomposite with $10 \% \mathrm{w} / \mathrm{w}$ of MLG. This fact is explained by the electrical conductivity and dielectric properties of the nanocomposites. MLG nanocomposites act as a capacitor while MWCNT nanocomposites behave as conductor materials. Regarding the heating homogeneity of the nanocomposites it can be concluded that $1 \%$ of MWCNT is the most suitable MWCNT for polypropylene matrix as the diference between the mean, maximum and minimum temperature is very narrow. Dispersion 
analysis showed few agglomerates of MWCNT in polypropylene matrix which do not showed a negative effect on the microwave radiation absorption. These agglomerates could produce hot spots but the heating homogeneity of PP $+1 \%$ of MWCNT demonstrate that these agglomerates do not affect negatively on the heating behaviour under microwave radiation.

\section{REFERENCES}

${ }^{1}$ Rudnev, V., Loveless, D. et al. Handbook of Induction Heating. Marcel Dekker AG, Basel, (2003).

${ }^{2}$ T.Bayerl, A.Benedito, A.Gallego, B.Galindo, P.Mitschang. Melting of polymer-polymer composites by Particulate heating promoters and electromagnetic radiation. Synthetic PolymerPolymerComposites, Carl Hanser Verlag GmbH \& CO. KG (2011).

${ }^{3}$ National Research Centre (NRC), Microwave Processing of Materials, National Materials Advisory Board, Commision onm Engineering and Technical Systems, National Academy Press, USA, (1994).

4 J. Harper, D. Price, "Use of fillers to enable the microwave processing of polypropylene", Microwave Power \& Electromagnetic Energy 40, pp. 219-227, (2007).

5 J. A. Menéndez, A. Arenillas, "Microwave heating processes involving carbon materials", Fuel Processing Technology 91, pp. 1-8, (2010).

${ }^{6}$ F. Liu, X. Qian, X. Wu, "The response of carbon black filled high-density polyethylene to microwave processing", Journal of Materials Processing Technologies 210, pp. 1991-1996, (2010).

7 A.A. Al-Ghamdi, Farid El-Tantawy, "New electromagnetic wave shielding effectiveness at microwave frequency of polyvinyl chloride reinforced graphite/copper nanoparticles", Composites: Part A 41, pp. 1693-1701, (2010).

${ }^{8}$ J.A.Aguilar-Garib, F.Garcia, Z.Valdez. Journal of Ceramic Society of Japan, 117, 7, 801-807 (2009).

${ }^{9}$ Harper, J. Price, D. Zhang, J. Journal of Microwave Power \& Electromagnetic Energy. Vol.40, No.4, pp. 219-227, (2007).

${ }^{10}$ J.E. Atwater, R.R. Wheeler, "Temperature dependent complex permittivity of graphitized carbon blacks at microwave frequencies between 0.2 and $26 \mathrm{GHz}$, Material Science 39, pp. 151-157, (2004).

${ }^{11} \mathrm{H}$. Lin, H. Zhu, "Microwave absorbing properties of co-filled carbon nanotubes", Materials Research Bulletin 43, pp. 2697-2702, (2008).

${ }^{12}$ L. Zhang, H. Zhu, "Dielectric, magnetic and microwave absorbing properties of multi-walled carbon nanotubes filled with $\mathrm{Sm}_{2} \mathrm{O}_{3}$ nanoparticles", Materials Letters 63, pp. 272-274, (2009).

${ }^{13}$ Peng Zhihua, Peng Jingcui, Peng Yanfeng, "Complex permittivity and microwave absorption properties of carbon nanotubes/polymer composite: A numerical study", Physics Letters A372, pp. 3714-3718, (2008).

${ }^{14}$ Zhuangjun Fan, Guohua Luo, Zengfy Zhang, "Electromagnetic and microwave absorbing properties of multi-walled carbon nanotubes/polymer composites", Material Science and Engineering B 132, pp. 85-89, (2006).

${ }_{15} \mathrm{~J}$. Harper, D. Price, "Use of fillers to enable the microwave processing of polypropylene", Microwave Power \& Electromagnetic Energy 40, pp. 219-227, (2007).

${ }^{16}$ Gaurav R. Kasaliwal, Andreas Goldel, Petra Potschke*, Gert Heinrich, "Influences of polymer matrix melt viscosity and molecular weight on MWCNT agglomerate dispersion", Polymer, Volume 52, Issue 4,1027-1036, (2011)

${ }^{15}$ G. Raju. Dielectrics in Electric Fields, CRC Press, 2003. 
${ }^{16}$ T.S. Sorensen, V. Compañ, J. Chem. Soc. Faraday Trans., 91 (23) 1996, 4235-4250.

17.J.C. Maxwell. A treatise of Electricity \& Magnetism, Dover N.Y, 1954.

18. K.W. Wagner, Arch. Elektrotech, 2, 1914, 371,

${ }^{19}$. K.W. Wagner, Arch. Elektrotech, 3, 1914, 67.

${ }^{20}$. R.W Sillars, Proc. Inst. Electr. Eng. London, 80, 1937, 378.

${ }^{21}$ Drüschler, M.; Huber, B.; Roling, B. J. Phys. Chem. C 2011, 115, 6802.

22. J. Tang, M. Radosz, Y. Shen, Macromolecules 41, 2008, 493.

23. M.M. HHuang, H. Weingärtner, CHemPhysChem 9, 2008, 2172.

${ }^{24}$. V. Sans, et al. Chem. Eur. 17, 2011, 1894-1906. 


\section{LIST OF TABLES}

Table 1: Particle analysis of Nanocomposites

Table 2: Values of the conductivity measured at $20^{\circ} \mathrm{C}$ for all the samples studied

Table 3: Heating efficiency of nanocomposites

\section{LIST OF FIGURES}

Figure 1. SEM PP + 1\% MLG: a) 2350x, b) $8000 x$

Figure 2. SEM PP + 1\% MWCNTs: a) 7400x, b) 16000x

Figure 3. Optical microscope: a) PP + 1\% MLG, b) PP + $1 \%$ MWCNTs

Figure 4. Frequency dependence of imaginary permitivity for PP+MWCNT at $50^{\circ} \mathrm{C}$ of temperature

Figure 5. Frequency dependence of impedance for PP+MLG at different percentage of Graphene, $0,5 \%, 1 \%$, $3 \%, 5 \%$ and $10 \%$ measured at $50{ }^{\circ} \mathrm{C}$ of temperature. In secondary axis OY we plot the phase angle for the same samples at the same temperature of $50^{\circ} \mathrm{C}$ in open symbols

Figure 6. Double logarithmic plot of the absolute value of impedance as a function of the frequency for a) samples PP+MGL and b) samples of PP+MWCNT at $50^{\circ} \mathrm{C}$

Figure 7. Geometrical capacitance as a function of the composition in \% of MLG fillers in samples of PP+MLG

Figure 8. Variation of the real part of the samples permittivity as a function of the temperature

Figure 9. Variation of the loss tangent with the amount of filler concentration for all the samples at all the temperatures studied

Figure 10. Microwave heating efficiency of MWCNT nanocomposites

Figure 11. Microwave heating efficiency of MLG nanocomposites

Figure 12. Microwave heating of MWCNT nanocomposites

Figure 13. Microwave heating of MWCNT nanocomposites 


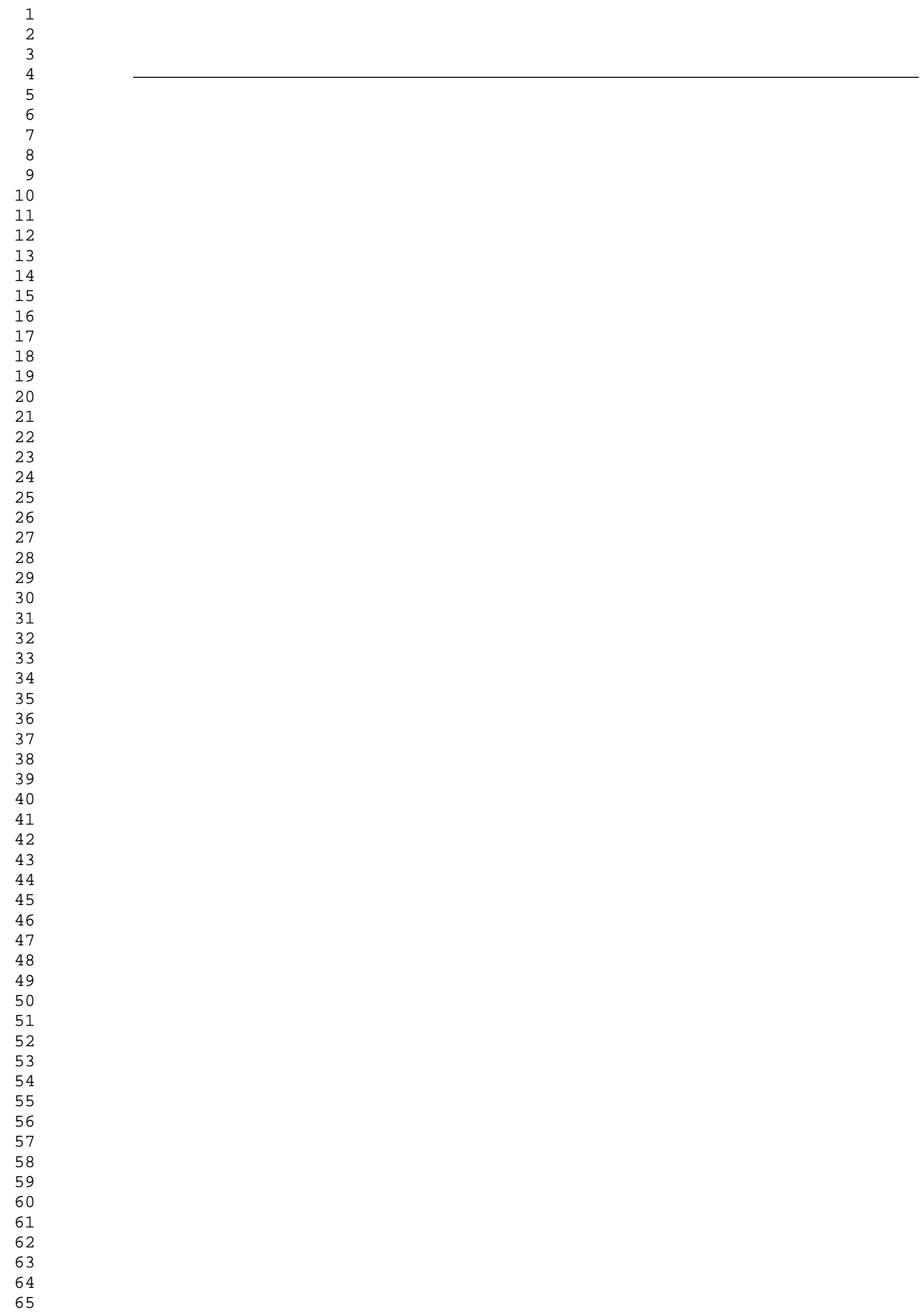


Table 1

Table 1: Particle analysis of nanocomposites

\begin{tabular}{|l|c|c|}
\hline & Mean Particle Size $(\mu \mathrm{m})$ & Agglomerates density (\%) \\
\hline $\mathrm{PP}+1 \% \mathrm{w} / \mathrm{w}$ MLG & 10.26 & 3.1 \\
\hline $\mathrm{PP}+1 \% \mathrm{w} / \mathrm{w}$ MWCNT & 15.56 & 0.36 \\
\hline
\end{tabular}


Table 2. Values of the conductivity measured at $20^{\circ} \mathrm{C}$ for all the samples studied.

\begin{tabular}{|c|c|c|c|c|c|}
\hline Sample & \multicolumn{5}{|c|}{ Conductivity (S/cm) } \\
\hline $\begin{array}{c}\text { Nanoparticle } \\
\text { content }\end{array}$ & $0.5 \%$ & $1 \%$ & $3 \%$ & $5 \%$ & $10 \%$ \\
\hline PP+MLG & $0.4 \times 10^{-6}$ & $2.5 \times 10^{-6}$ & $2.4 \times 10^{-6}$ & $2.3 \times 10^{-6}$ & $1.0 \times 10^{-6}$ \\
\hline PP+MWCNT & $2.0 \times 10^{-6}$ & $4.5 \times 10^{-5}$ & $8,3 \times 10^{-4}$ & $2.2 \times 10^{-3}$ & - \\
\hline
\end{tabular}


Table 3

Table 3: Heating efficiency of nanocomposites

\begin{tabular}{|c|c|c|}
\hline \multirow{2}{*}{ Heating time (s) } & \multicolumn{2}{|c|}{ Heating efficiency $(\stackrel{\circ}{ } \mathrm{C} / \%)$} \\
\cline { 2 - 3 } & MWCNT & MLG \\
\hline 20 & 16.6 & 3.1 \\
\hline 40 & 27.7 & 4.9 \\
\hline 60 & 34.6 & 5.7 \\
\hline
\end{tabular}


Click here to download high resolution image

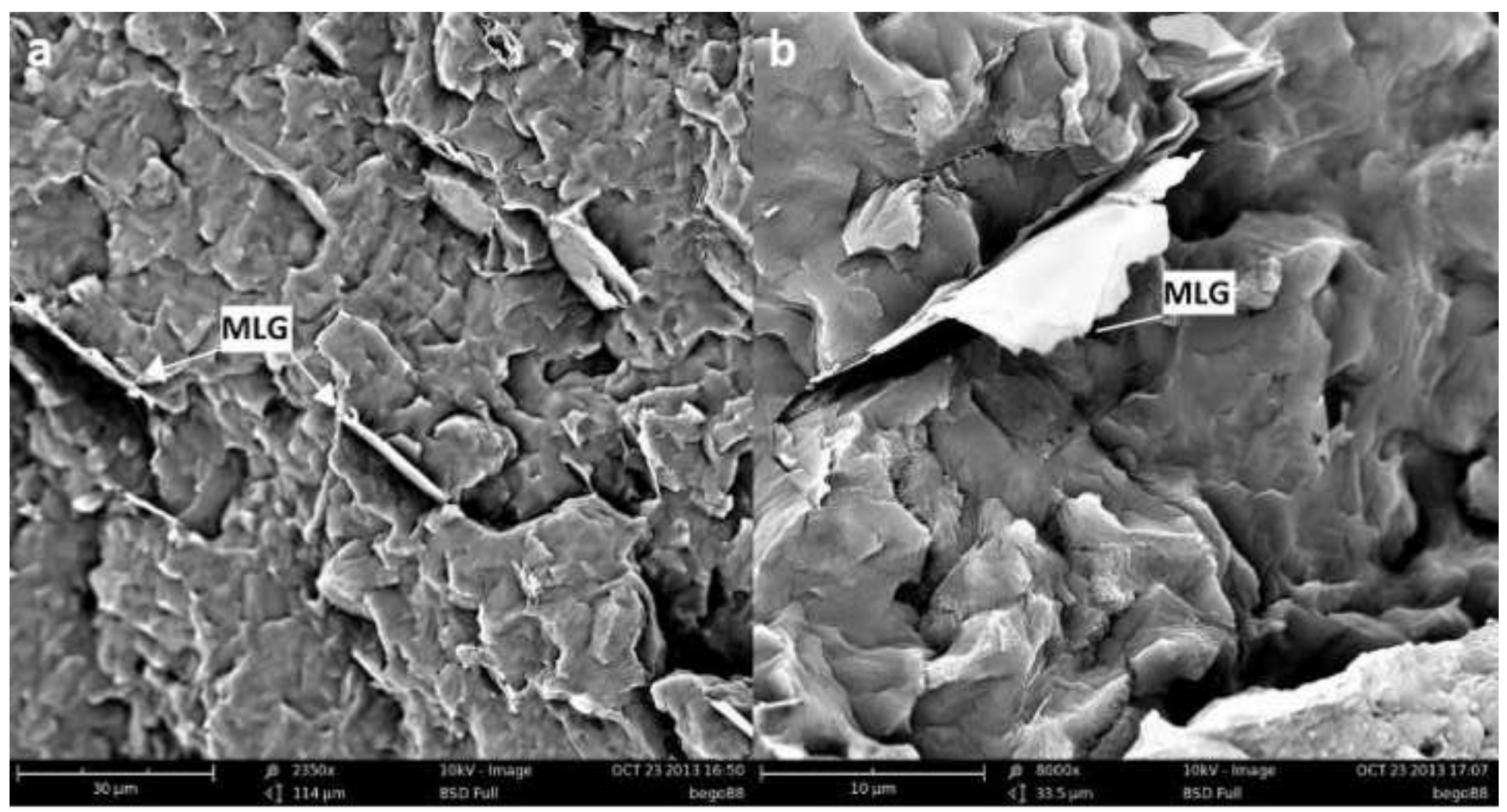


Click here to download high resolution image
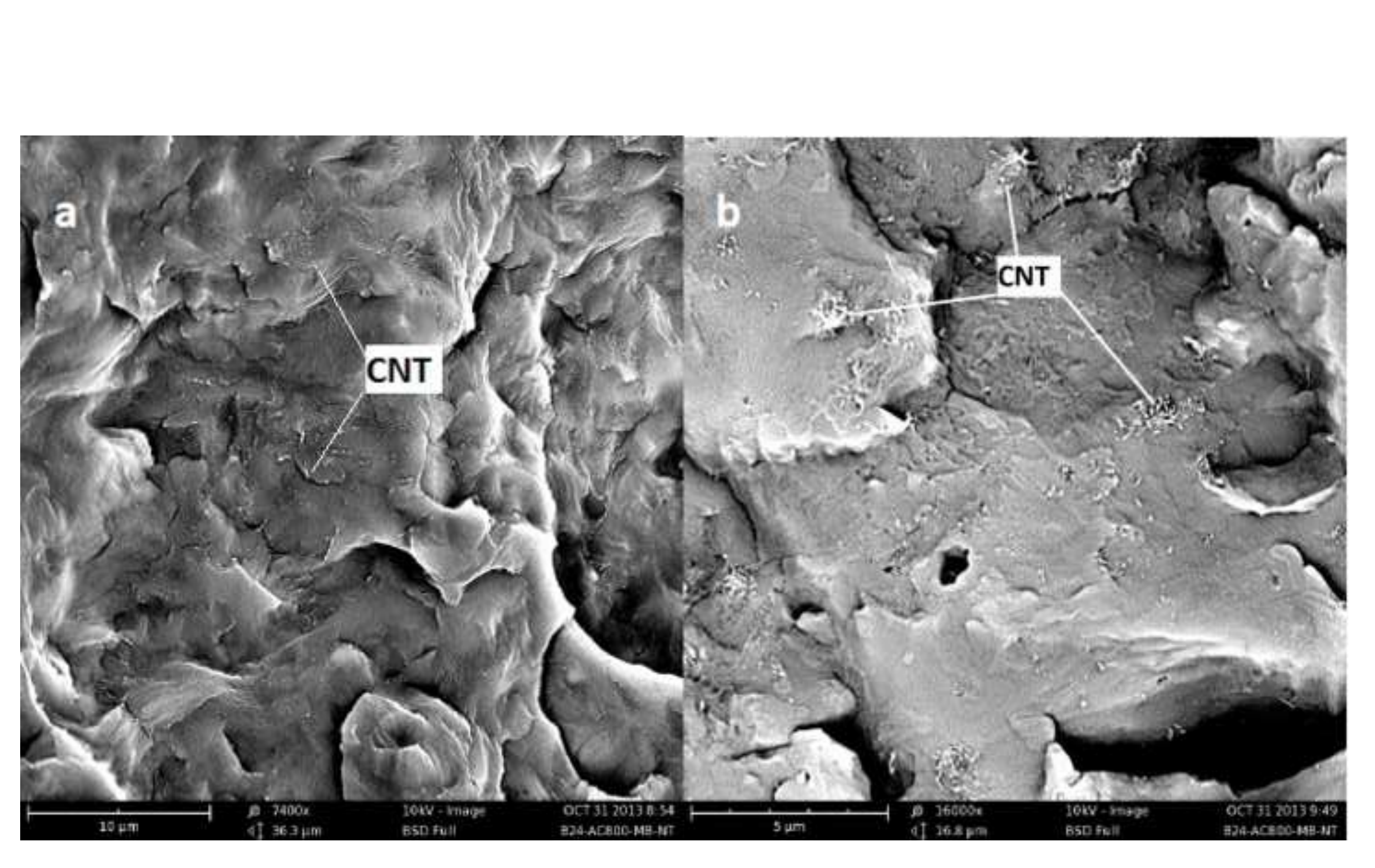

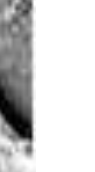

.


Click here to download high resolution image

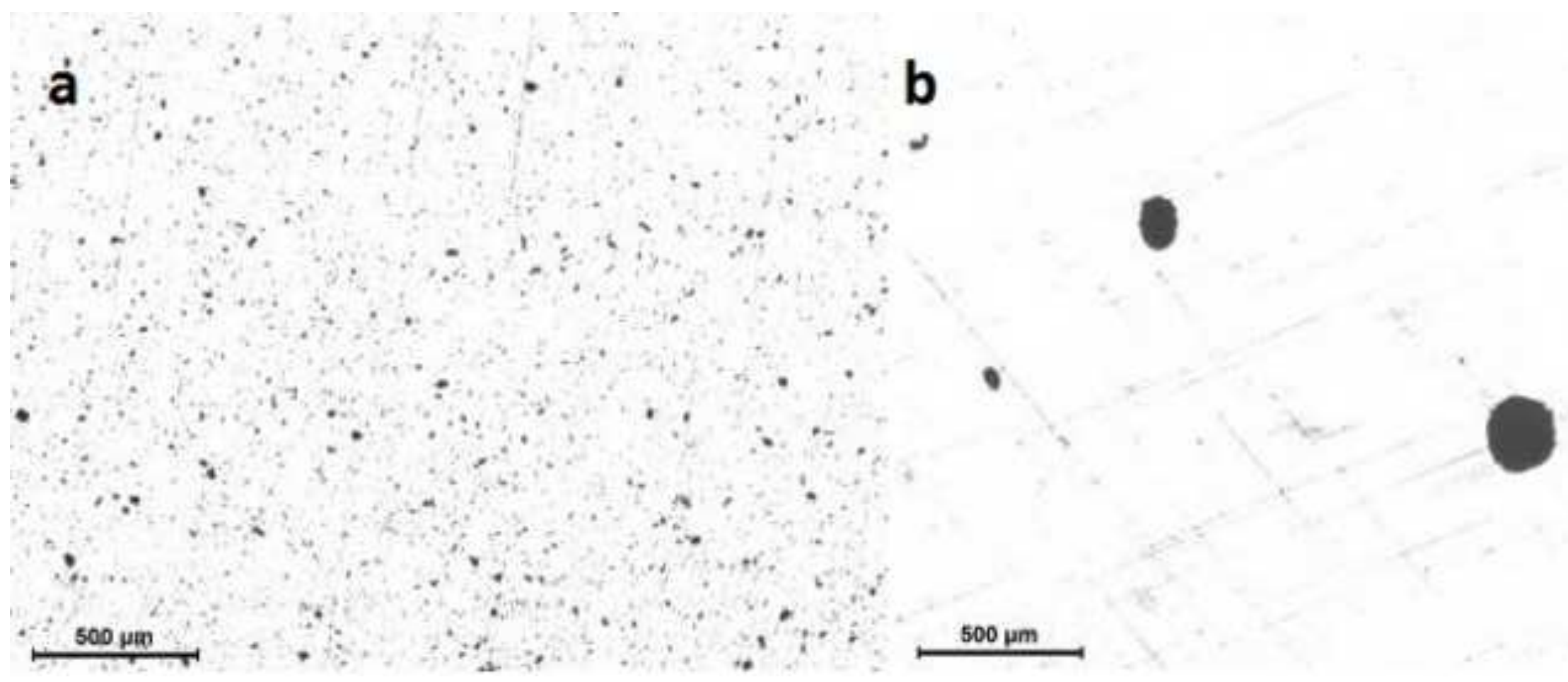




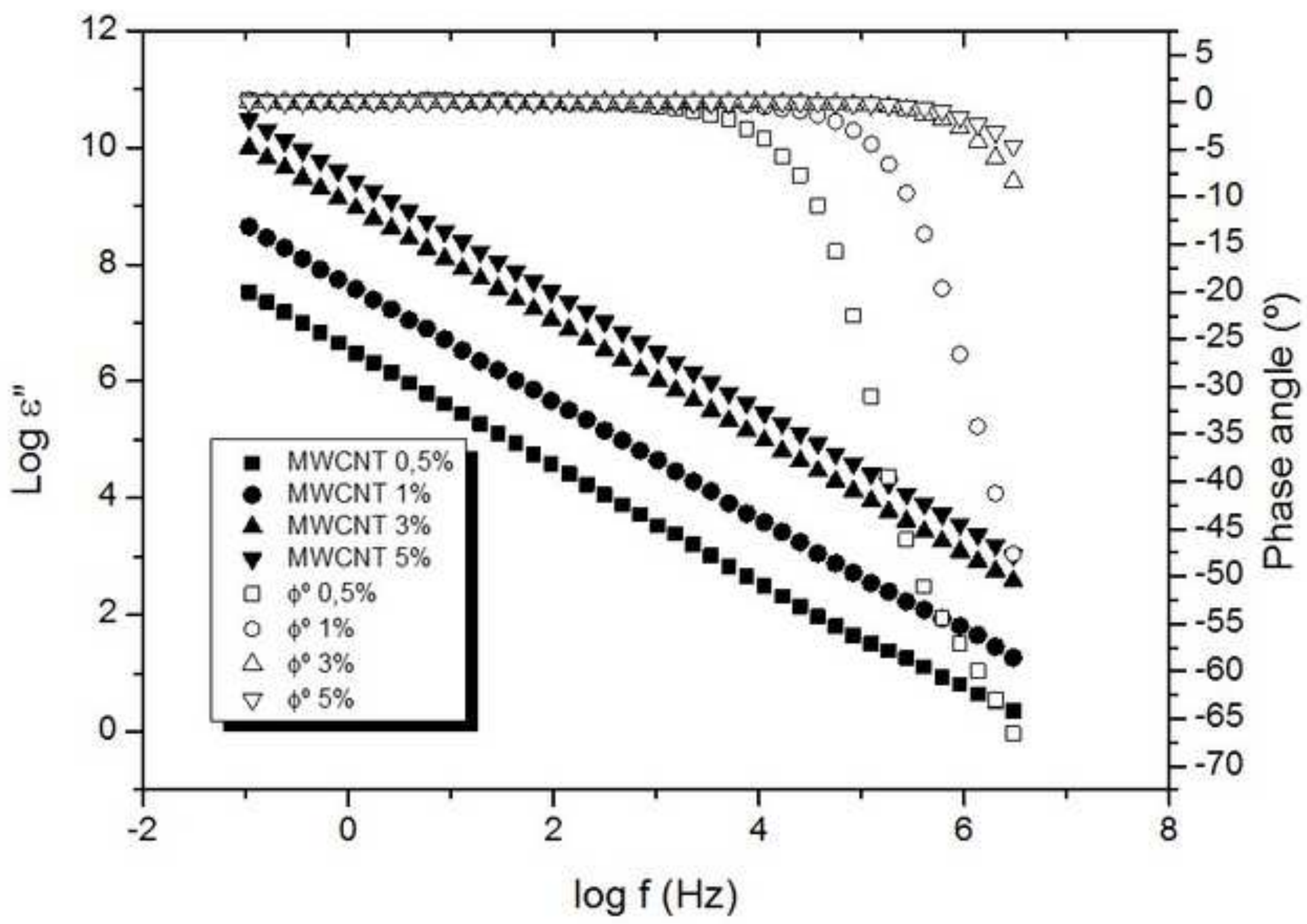




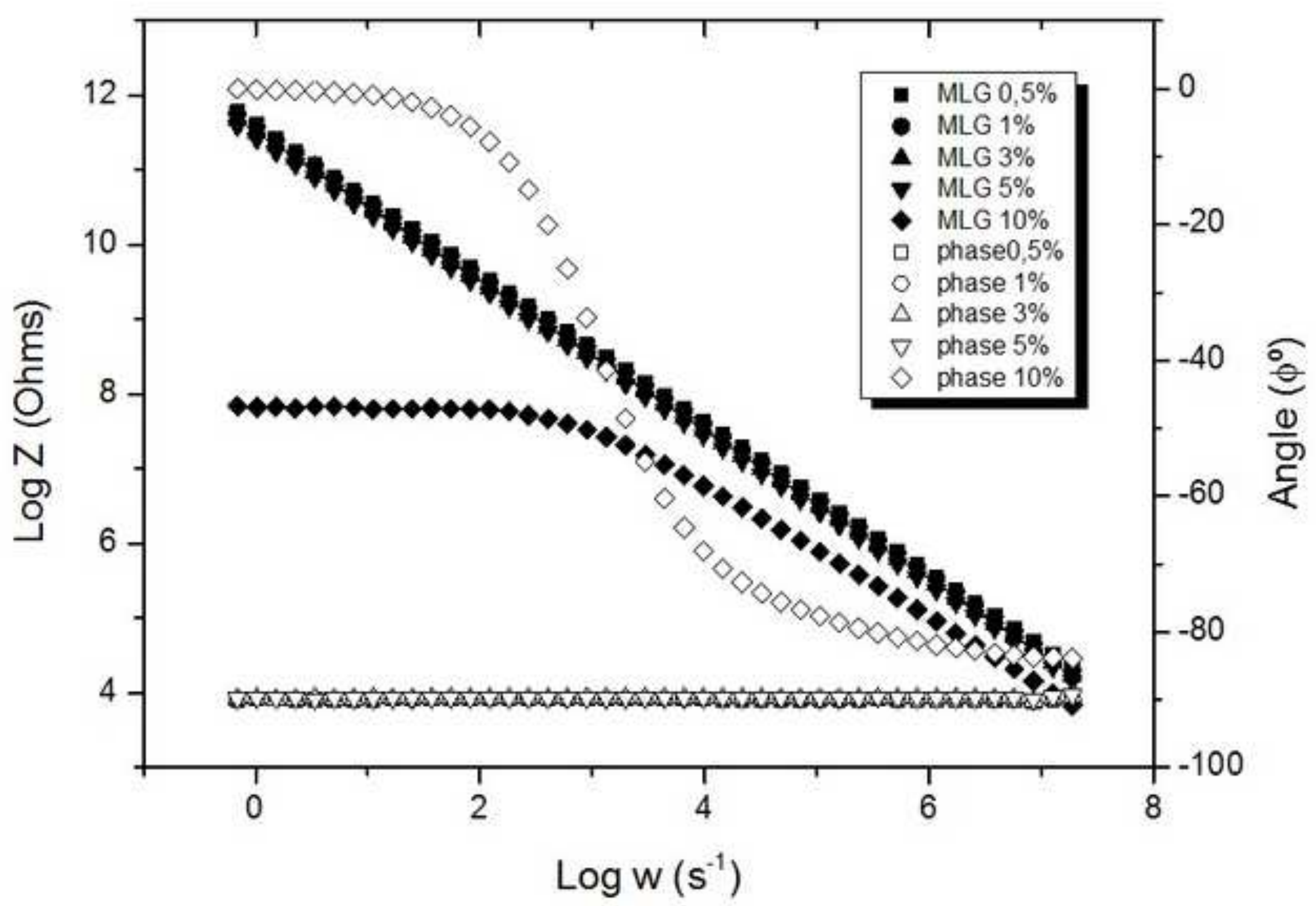




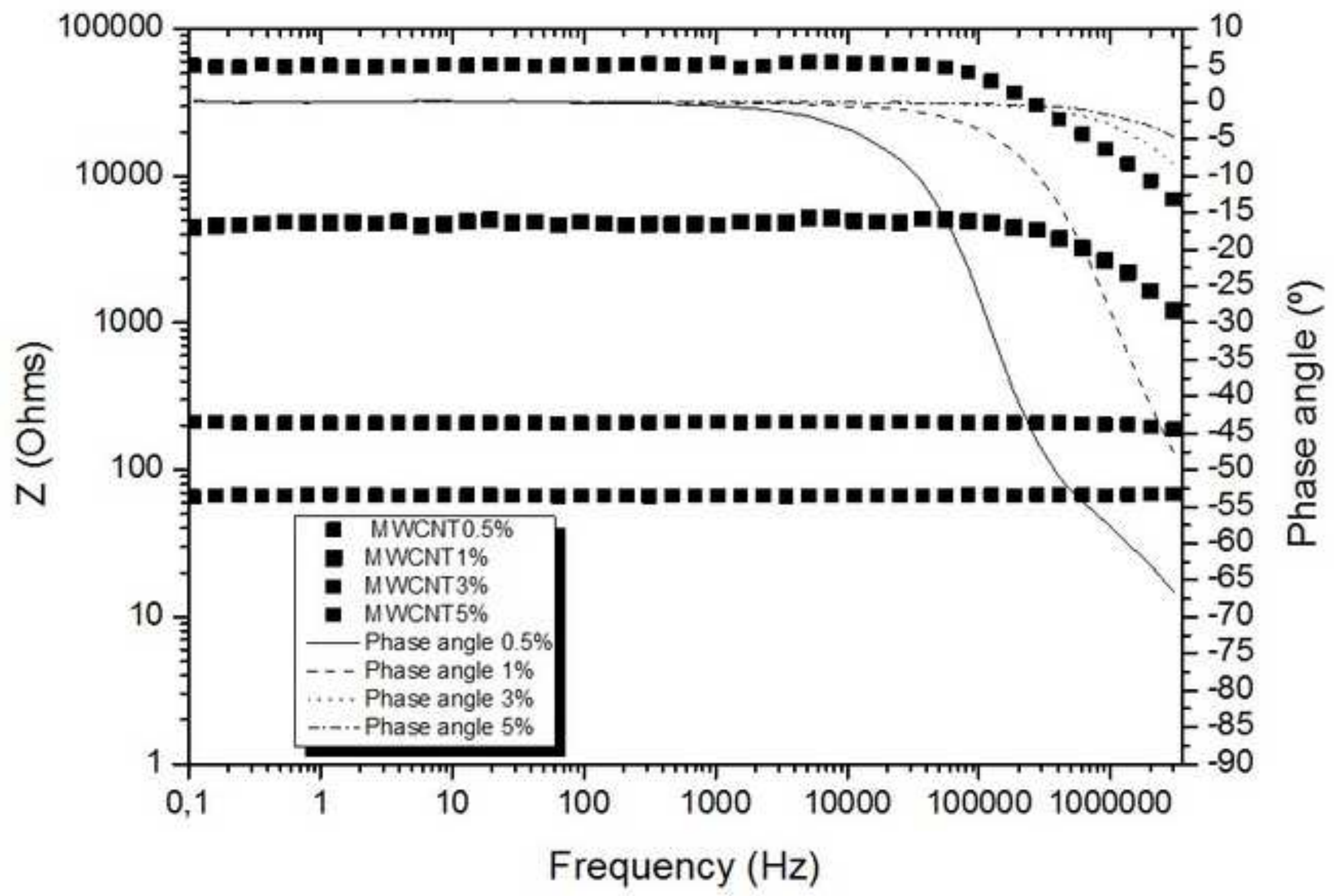


Click here to download high resolution image

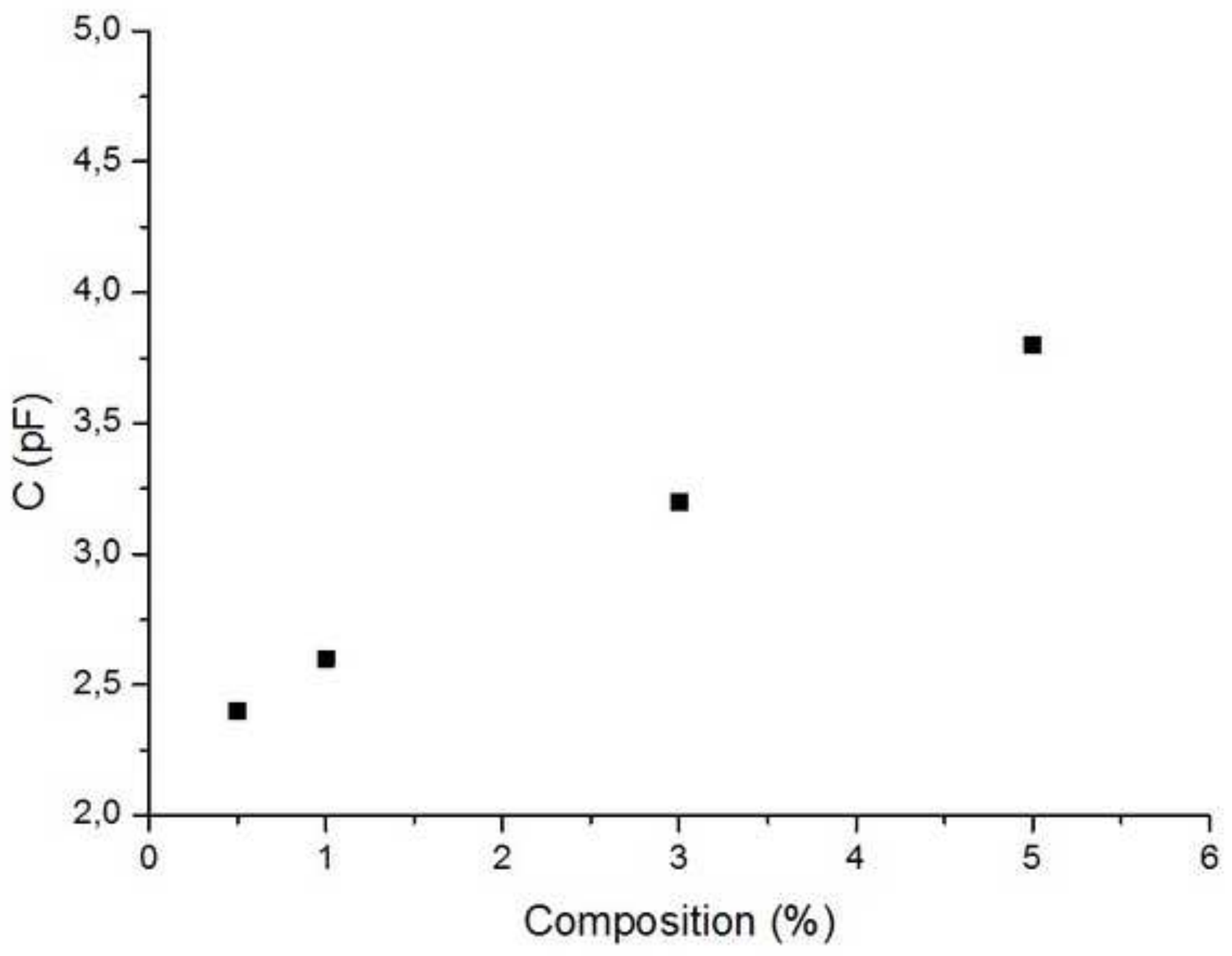




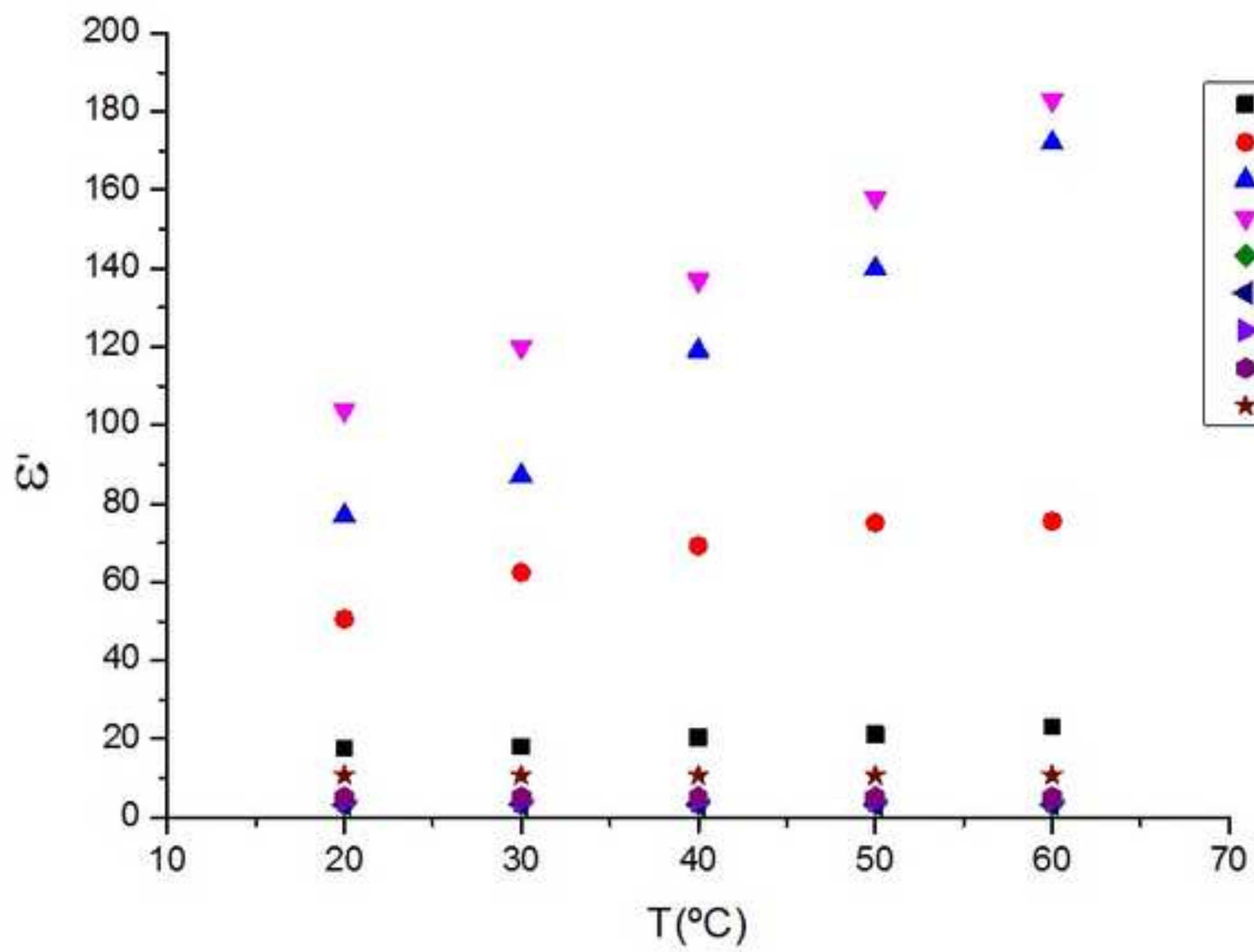




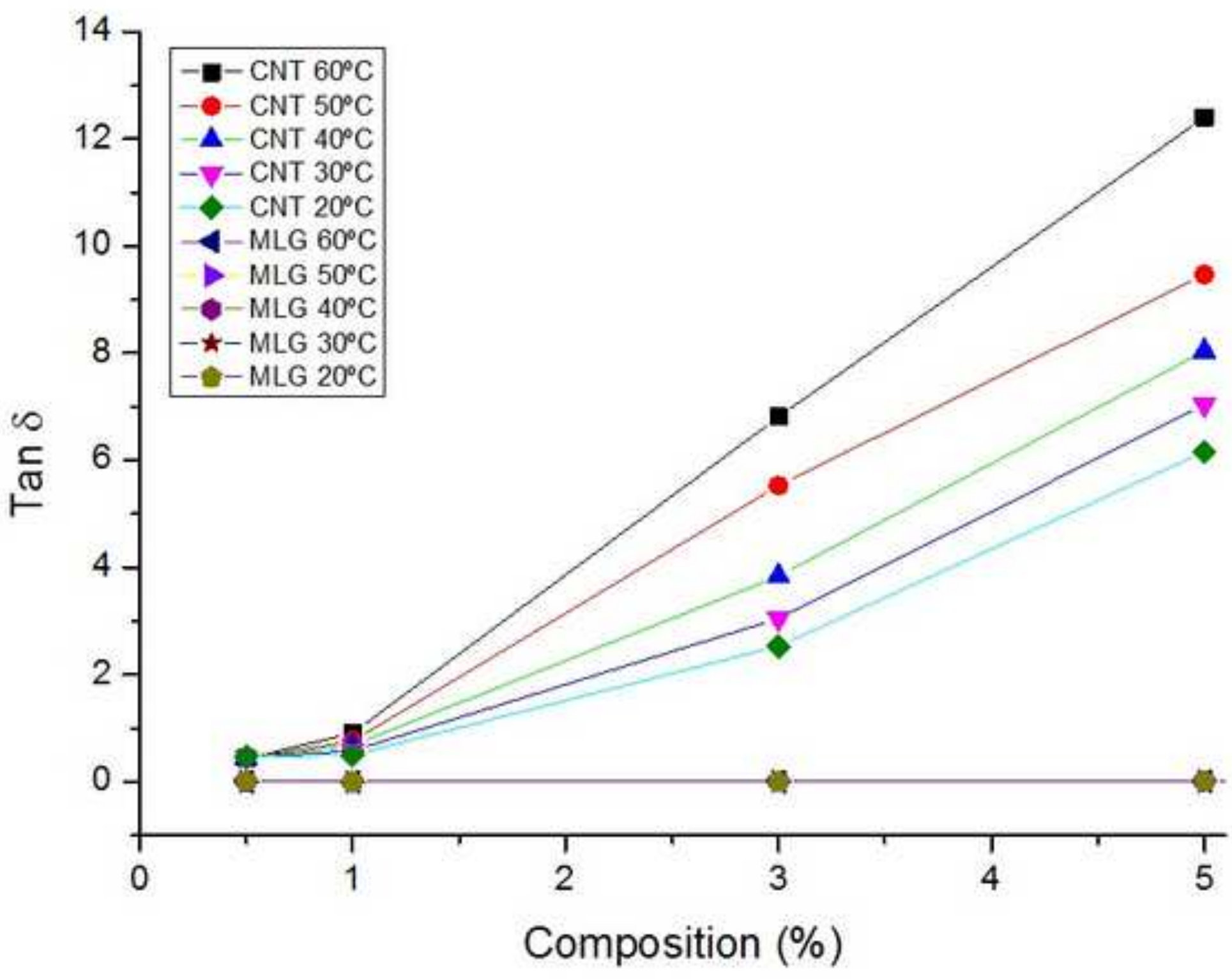


Click here to download high resolution image

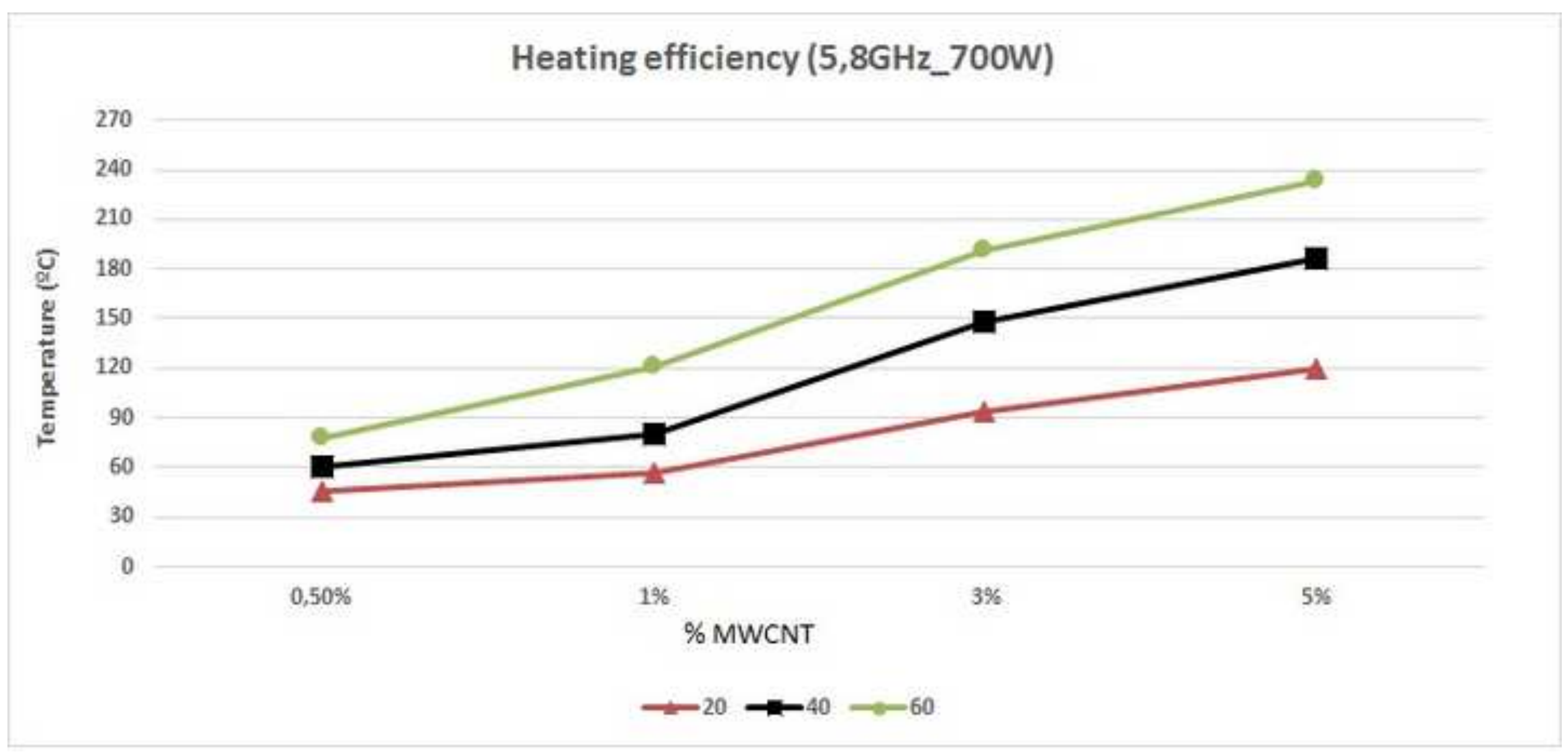


Figure 11
Click here to download high resolution image

\section{Heating efficiency $(5,8 \mathrm{GHz}$-700W)}

90

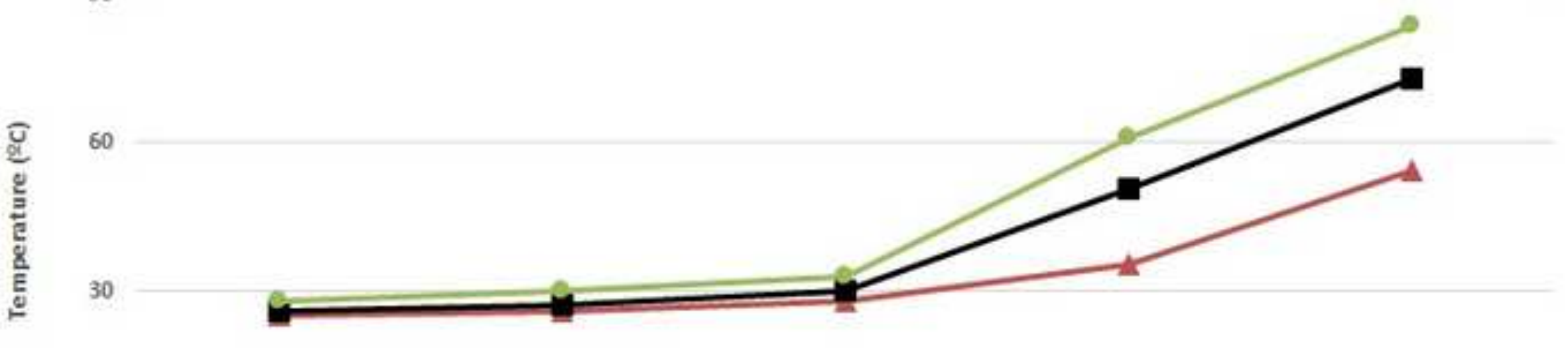

0

$0.50 \%$

$1 \%$

$3 \%$

$5 \%$

$10 \%$

\% MLG

$-20 \rightarrow 40 \longrightarrow 60$ 
Click here to download high resolution image

\section{0 s heating time $-700 \mathrm{~W}$}

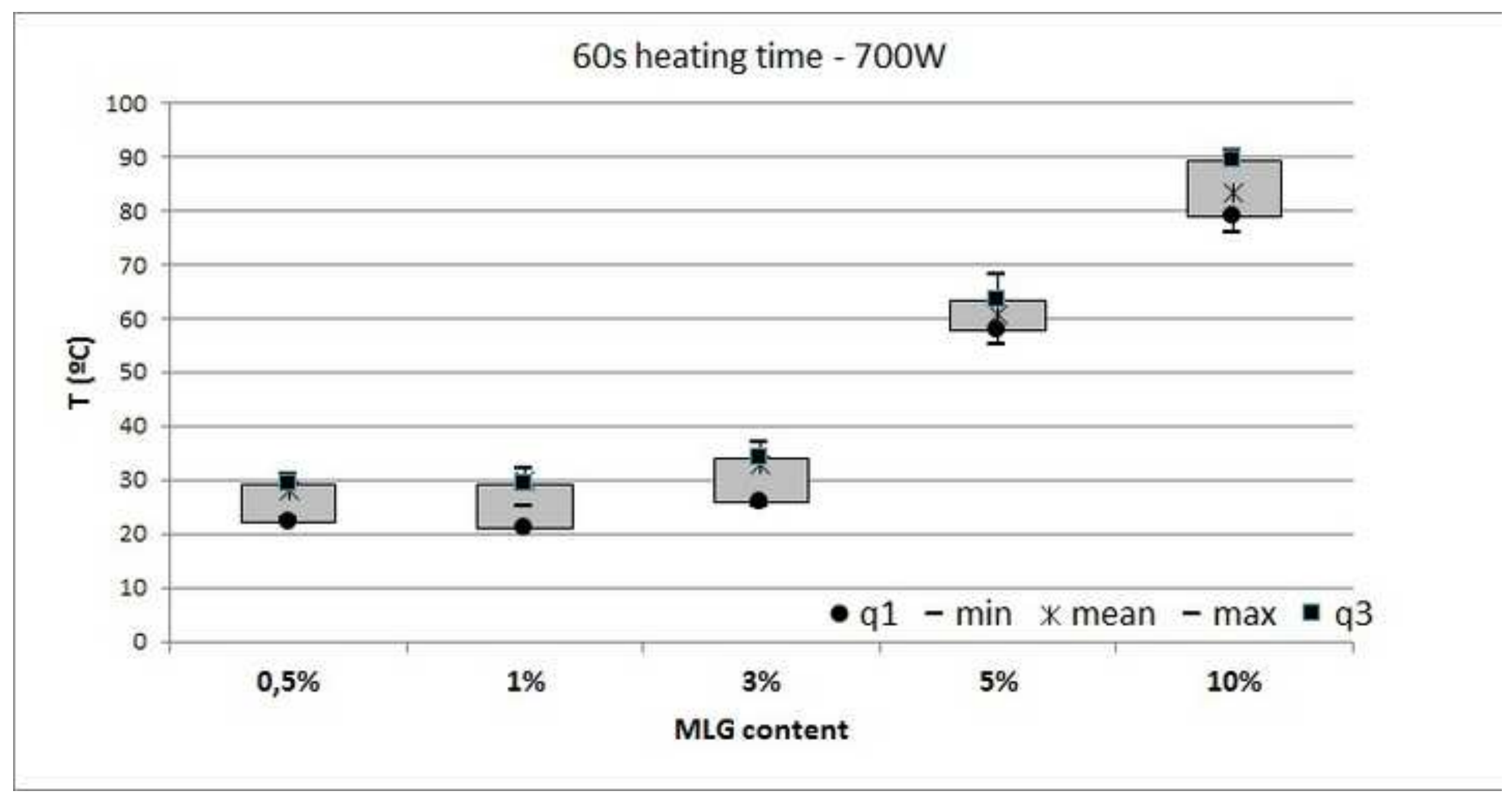


Click here to download high resolution image

\section{0 s heating time $-700 \mathrm{~W}$}

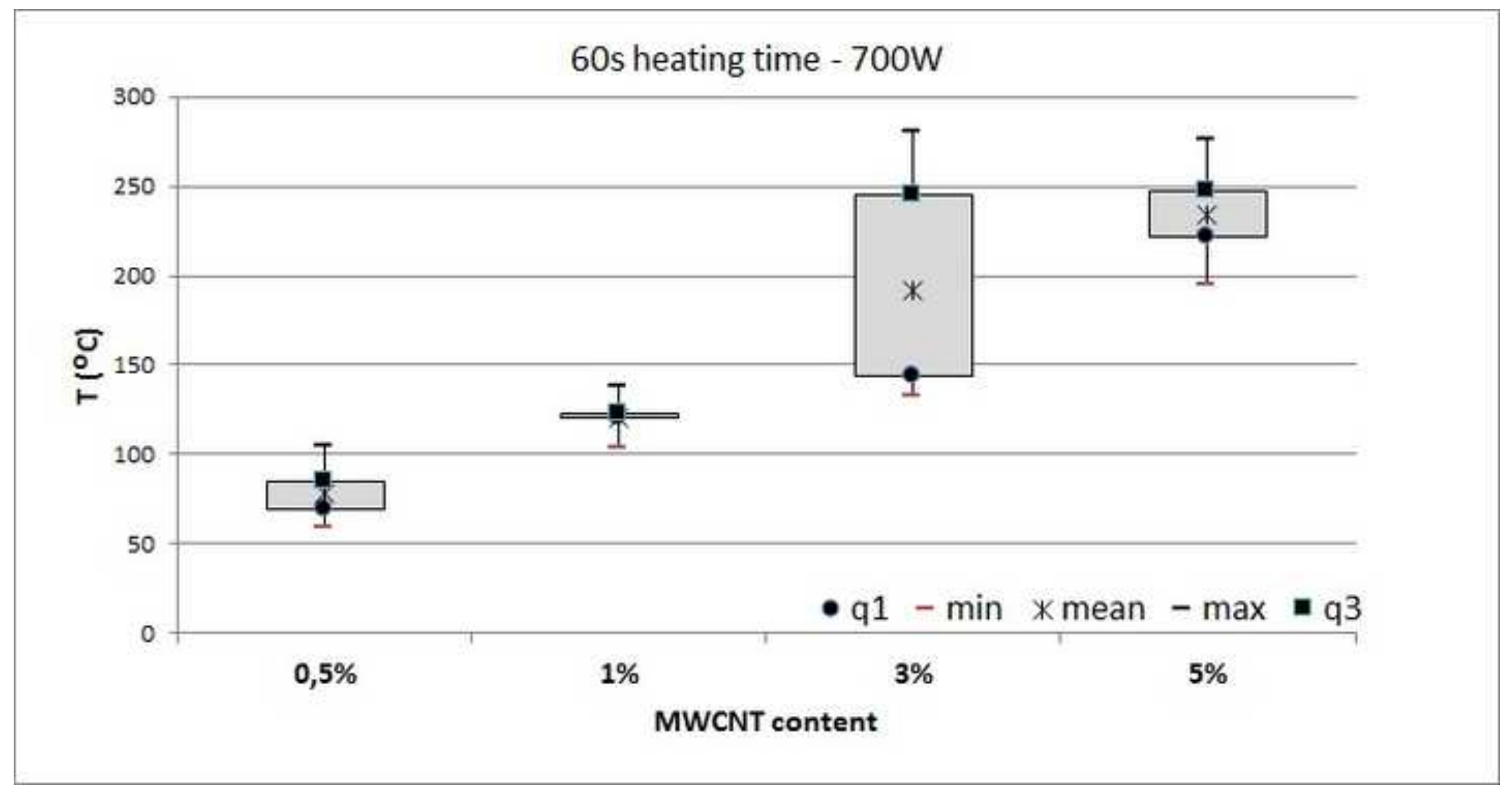

